\title{
Comparison of cardiorespiratory effects of terbutaline and salbutamol aerosols in patients with reversible airways obstruction
}

\author{
LUKE HAR R IS \\ Respiratory Physiology Laboratory, Fazakerley Hospital, Liverpool 9
}

\begin{abstract}
Harris, L. (1973). Thorax, 28, 592-595. Comparison of cardiorespiratory effects of terbutaline and salbutamol aerosols in patients with reversible airways obstruction. The effects of pressurized aerosol administration of terbutaline were compared with those of salbutamol in 14 patients with at least $20 \%$ reversibility of airways obstruction. The two drugs were found to be equipotent bronchodilators in the dosage used. Salbutamol was found to produce significant increases in minute ventilation, physiological dead space/tidal volume ratio, and ventilatory equivalent for oxygen, with significant falls in arterial oxygen tension and heart rate. Terbutaline did not induce significant changes in any of these variables. These results suggest that terbutaline is less likely than salbutamol to have an adverse effect upon ventilation-perfusion relationships.
\end{abstract}

Among the newer $\beta$-adrenergic stimulating bronchodilators, terbutaline (Carlström, 1970) and salbutamol (Lewis, 1971) have been shown to be relatively selective $\beta$-2 stimulators.

The oral preparations of these two drugs have been compared by Legge, Gaddie, and Palmer (1971), who found no significant difference between them. Freedman (1972) demonstrated that $100 \mu \mathrm{g}$ salbutamol and $250 \mu \mathrm{g}$ terbutaline by aerosol administration had an equipotent bronchodilating effect without any clinically important side effects.

The present study is a more detailed comparison of cardiorespiratory variables following the administration of the two substances by pressurized aerosol in twice the dosages used by Freedman.

\section{MATERIAL}

Fourteen volunteers were studied as outpatients. All were men (age 35-65, mean 55.5) shown repeatedly to have reversibility of airways obstruction by at least $20 \%$ increase in forced expiratory volume in 1 second $\left(\mathrm{FEV}_{1}\right)$ after administration of a bronchodilator. All had previously taken part in similar studies. Comparisons were acceptable only if $F E V_{1}$ values after placebo agreed within $10 \%$ on the test days. Initially, 18 patients were entered for the trial but 4 were excluded from future study because of wide fluctuations in baseline $\mathrm{FEV}_{1}$ measurements on the test days.
METHODS

The study was designed as a 'within-patient' trial. Each patient attended at the same time on the same day of the week on two successive weeks. At each visit baseline measurements were made 30 minutes after two inhalations from an aerosol device containing only propellant ('placebo'). Measurements were then repeated 30 minutes after two inhalations of either terbutaline or salbutamol ('active'). The order for allocation of active aerosol was randomized. At the conclusion of the trial it was found that eight patients had used terbutaline on the first visit and six had used salbutamol first. Placebo and active aerosols were indistinguishable to the patients, although the operator was aware that placebo was being used for baseline measurements. The use of propellant alone in this way compensates for any placebo effect of $N$ using an aerosol device and for any possible effect N of the propellant itself. Prior to each study day the patients abstained from all their usual therapy for at least 12 hours (including corticosteroid in three patients). The dosage delivered by two activations of $\mathbb{D}$ the aerosol devices was $500 \mu \mathrm{g}$ terbutaline and 200 ? $\mu \mathrm{g}$ salbutamol respectively. Measurements were made $\square$ at 30 minutes because previous reports (Kennedy and Simpson, 1969 ; Legge et al., 1971) have shown that both drugs can be expected to produce maximum bronchodilatation at that time, and possible adverse effeots not persisting for 30 minutes are unlikely to be clinically important. 
The aerosol was, on every occasion, manipulated by the investigator personally. The $F E V_{1}$ was taken as the best of three attempts on a Vitalograph spirometer. Values were corrected to body temperature and pressure, saturated (BTPS).

Minute ventilation was measured as inspiratory volume ( $\dot{V} I)$ over a 5-minute period with a ParkinsonCowan dry gas meter, and respiratory frequency (f) was recorded simultaneously. VI was converted to expiratory volume $\left(\dot{V}_{E}\right.$ by the formula $\dot{V}_{E}=\dot{V}_{I} X$ FIN2/ FEN2 and corrected to BTPS. The patients were allowed to get used to the noseclip and mouthpiece, and measurements were recorded only after $\dot{V} I$ had become stabilized over a period of at least 3 minutes. Expired air was collected for 5 minutes in a 100 litre Douglas bag using a low-resistance one-way valve and was analysed for $\mathrm{CO}_{2}$ and $\mathrm{O}_{2}$. Nitrogen was calculated as $100-\mathrm{FE}_{02}-\mathrm{FE}_{\mathrm{CO} 2}$. Oxygen was measured with a Servomex paramagnetic $\mathrm{O}_{2}$ analyser calibrated with oxygen-free nitrogen and room air. Carbon dioxide was measured with an Hilger-IRD infrared $\mathrm{CO}_{2}$ analyser calibrated with gases of known $\mathrm{CO}_{2}$ and $\mathrm{O}_{2}$ content. Calibration gases were analysed for $\mathrm{CO}_{2}$ with a modified Haldane apparatus. Oxygen consumption $\left(\dot{\mathrm{VO}}_{2}\right)$ and carbon dioxide output $\left(\mathrm{V}^{2} \mathrm{CO}_{2}\right)$ were then calculated with correction to STPD.

As the subjects were volunteer outpatients and were required to attend on at least two occasions, it was decided to avoid arterial cannulation and cardiac catheterization because of the potential risk associated with these procedures.

Oxygenated mixed venous $\mathrm{PCO}_{2}$ was measured by a 'trial and error' rebreathing equilibration method using $\mathrm{CO}_{2} / \mathrm{O}_{2}$ mixtures of known composition until an acceptable plateau was obtained on the rapid $\mathrm{CO}_{2}$ analyser tracing (Hackney, Sears, and Collier, 1958). Blood gases and hydrogen ion concentration were measured on an IL blood gas analyser incorporating a Severinghaus type $\mathrm{PCO}_{2}$ microelectrode and a Clark type $\mathrm{PO}_{2}$ microelectrode. Samples were taken from the hyperaemic earlobe into heparinized capillary tubes and analysed promptly. The earlobe was rendered hyperaemic by vigorous massage for 3 minutes with a cream containing thurfyl nicotinate. Langlands and Wallace (1965) have reported a close correspondence between the results obtained from gas analysis of blood from the hyperaemic earlobe and that taken from the brachial artery, and MacIntyre, Norman and Smith (1968) have confirmed these findings with the technique used in the present study. Godfrey, Wozniak, Courtenay-Evans and Samuels (1971) have also confirmed the reliability of the method and have suggested correction factors. They state that no correction is required for $\mathrm{Po}_{2}$ but recommend a correction factor of $0.65 \mathrm{mmHg}$ to be added to the earlobe $\mathrm{PCO}_{2}$. This correction factor has been applied to the earlobe $\mathrm{PCO}_{2}$ measurements in this study. Physiological dead space tidal volume ratio was calculated from the formula, $\dot{V}_{D} / \dot{V}_{E}=1-$ $\left(\mathrm{PECO}_{2} / \mathrm{PaCO}_{2}\right)$ with correction for valve box dead space of $35 \mathrm{ml}$. Cardiac output was derived from the
Fick principle; that is $\mathrm{Q}_{\mathrm{T}}=\dot{\mathrm{V}} \mathrm{CO}_{2} / \mathrm{CVCO}_{2}-\mathrm{CaCO}_{2}$ with appropriate temperature and pressure corrections. Blood $\mathrm{CO}_{2}$ contents were derived from the tables of McHardy (1967). Alveolar oxygen tension ( $\mathbf{P}_{\mathrm{AO}_{2}-}$ was calculated from the formula, $\mathrm{PaO}_{2}=\mathrm{PIO}_{2}-$ $\mathrm{PaCO}_{2} / \mathrm{R}\left(\mathrm{PaCO}_{2} / \mathrm{R} \times \mathrm{FiO}_{2}\right.$ (1-R) ). The alveolararterial oxygen tension gradient $\left(\mathrm{A}-\mathrm{aDO}_{2}\right)$ was then obtained by subtraction.

\section{RESULTS}

Mean values ( \pm SEM) after placebo and after active aerosols are shown in the Table. Base line values after placebo for each variable show no significant differences on each of the two test days. Results were analysed by $t$ test.

VENTILATION AND GAS EXCHANGE The increase in FEV $_{1}(+37 \%)$ after active aerosol was identical for both groups and highly significant $(P<0.001)$. $\dot{V}_{E}$ was significantly increased after salbutamol $(\mathbf{P}<0.01) . \mathbf{V}_{\mathrm{D}} / \overrightarrow{\mathrm{V}}_{\mathrm{E}}$ was also increased after salbutamol whereas it was decreased after terbutaline, the difference between the means being significant $(\mathrm{P}<0.01)$. There were no significant changes in $\mathrm{f}$, $\mathrm{Vo}_{2}$ or $\mathrm{VCO}_{2}$ with either drug, but there was a significant increase in $\dot{V}_{E} / \hat{V o}_{2}$ after salbutamol $(\mathrm{P}<0.05)$.

BLOOD GASES Neither active aerosol produced any significant change in $\mathrm{PCO}_{2}$. Terbutaline did not produce any significant change in $\mathrm{Po}_{2}$ but salbutamol produced a significant fall in $\mathrm{PO}_{2} \quad(\mathrm{P}<0.05)$. Examination of individual $\mathrm{PO}_{2}$ changes showed that three patients had falls greater than $5 \mathrm{mmHg}$ after salbutamol $(-13,-10,-9)$ and two had such falls after terbutaline $(-9,-7)$. The patient with the lowest $\mathrm{PO}_{2}$ showed a fall of $4.5 \mathrm{mmHg}$ (from 50 to 45.5 ) with salbutamol but a rise of $6 \mathrm{mmHg}$ (from 54 to 60 ) with terbutaline. There were no significant differences in $\mathrm{A}-\mathrm{aDO}_{2}$ with either drug.

CARDIAC OUTPUT Accepting the well-known limitations of the indirect Fick $\mathrm{CO}_{2}$ method, the use of which in similar patients with increased metabolic rates is supported by Warell et al. (1970), there was no evidence of any change in cardiac output with either drug. The absence of significant changes in blood pressure and heart rate after terbutaline and in blood pressure with reduced heart rate $(P<0.05)$ after salbutamol are consistent with the cardiac output findings. 


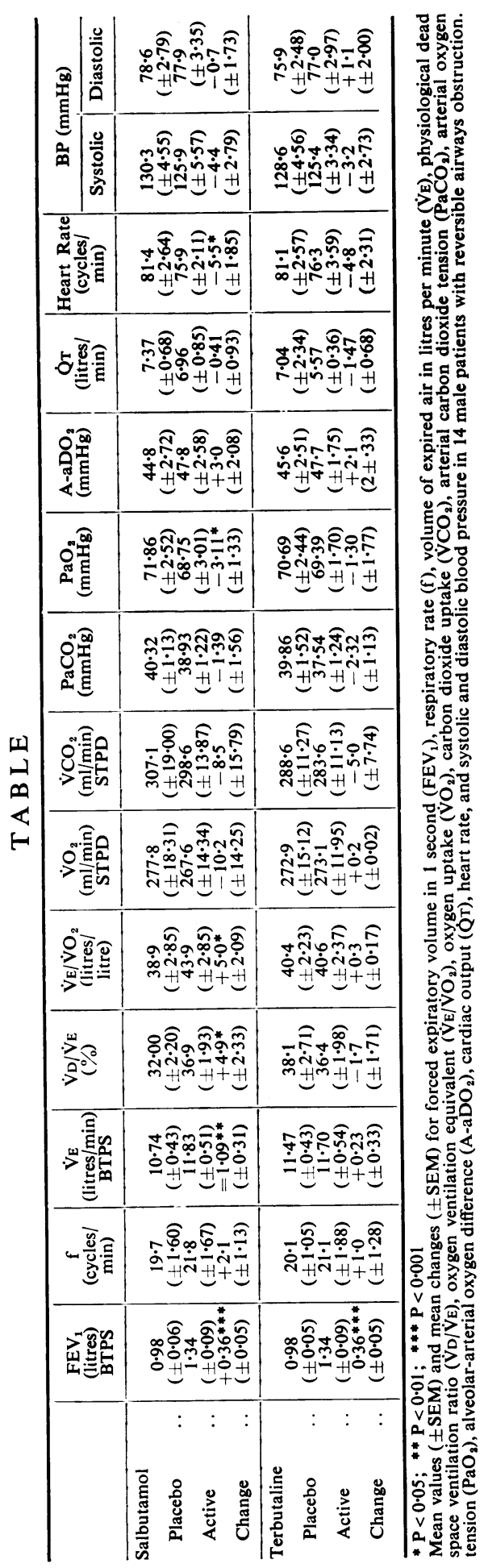




\section{DISCUSSION}

The results confirm that pressurized aerosol administration of terbutaline is as effective in producing bronchodilatation as is salbutamol. In the dosage used (salbutamol $200 \mu \mathrm{g}$, terbutaline $500 \mu \mathrm{g})$ they were equipotent and both show a wide dissociation between $\beta 1$ (cardiac) and $\beta 2$ (bronchial) effects. No side effects were noted in this dosage.

In general, the two drugs have much the same effects on most cardiorespiratory variables except that there appears to be an increase in 'wasted' ventilation after salbutamol, as shown by the increase in $\vec{V}_{D} / \vec{V}_{E}$ and $\vec{V}_{E} / \mathrm{Vo}_{2}$.

In addition, terbutaline seems to be less likely to produce increased hypoxaemia on the basis of group mean changes. However, two patients showed falls in $\mathrm{Po}_{2}$ greater than $5 \mathrm{mmHg}$ with terbutaline compared with three such falls after salbutamol, indicating that neither drug is entirely free from this hazard. Nevertheless, at the lowest $\mathrm{Po}$, which is where the real danger lies, salbutamol caused a fall whereas terbutaline produced a rise.

The literature concerning increased hypoxaemia induced by $\beta$-adrenergic stimulating drugs has been previously reviewed by the author (Harris, 1970, 1972 ), who suggested that it is the $\beta 2$ pulmonary vasodilator effect which is responsible by interfering with the homeostatic mechanism whereby blood flow is reduced to underventilated areas. This concept appears to be substantiated by the absence of change in cardiac output in the present study.

Having now reached the state of obtaining potent $\beta$-adrenergic stimulating bronchodilators with wide separation of $\beta 1$ and $\beta 2$ effects, the next stage of development might be the separation of the $\beta 2$ bronchodilator and vasodilator effects (in which case the latter might become known as $\beta 3$ effect).

The results presented suggest that terbutaline and salbutamol are equally effective bronchodilators when administered by pressurized aerosol, without cardiac effects, in the dosage used, and that terbutaline is less likely than salbutamol to cause increased hypoxaemia.
I wish to thank Mr. Kevin Lawton, principal biochemist, Fazakerley Hospital, for the blood gas analyses.

\section{REFERENCES}

Carlström, S. (Editor) (1970). Study on terbutaline, a new selective bronchodilating agent. Acta Medica Scandinavica, Suppl. p. 512.

Freedman, B. J. (1972). Trial of terbutaline aerosol in the treatment of asthma and a comparison of its effects with those of a salbutamol aerosol. British Journal of Diseases of the Chest, 66, 222.

Godfrey, S., Wozniak, E. R., Courtenay-Evans, R. J., and Samuels, C. S. (1971). Ear lobe blood samples for blood gas analysis at rest and during exercise. British Journal of Diseases of the Chest, 65, 58.

Hackney, J. D., Sears, C. H., and Collier, C. R. (1958). Estimation of arterial $\mathrm{CO}_{2}$ tension by rebreathing technique. Journal of Applied Physiology, 12, 425.

Harris, L. H. (1970). Effects of isoprenaline plus phenylephrine by pressurized aerosol on blood gases, ventilation, and perfusion in chronic obstructive lung disease. British Medical Journal, 4, 579.

- (1972). Comparison of the effect on blood gases, ventilation, and perfusion of isoproterenol-phenylephrine and salbutamol aerosols in chronic bronchitis with asthma. Journal of Allergy and Clinical Immunology, 49, 63.

Kennedy, M. C. S., and Simpson, W. T. (1969). Human pharmacological and clinical studies on salbutamol, a specific beta-adrenergic bronchodilator. British Journal of Diseases of the Chest, 63, 165.

Langlands, J. H. M., and Wallace, W. F. M. (1965). Small blood-samples from ear-lobe puncture: a substitute for arterial puncture. Lancet, 2, 315.

Legge, J. S., Gaddie, J., and Palmer, K. N. V. (1971). Comparison of two oral selective $\beta 2$-adrenergic stimulant drugs in bronchial asthma. British Medical Journal, 1, 637.

Lewis, A. A. G. (Editor) (1971). Salbutamol. Postgraduate Medical Journal, March Suppl. vol. 47.

MacIntyre, J., Norman, J. N., and Smith, G. (1968). Use of capillary blood in measurement of arterial $\mathbf{P O}_{2}$. British Medical Journal, 3, 640.

McHardy, G. J. R. (1967). The relationship between the differences in pressure and content of carbon dioxide in arterial and venous blood. Clinical Science, 32, 299.

Warell, D. A., Robertson, D. G., Howes, J. N., Connolly, M. E., Patterson, J. W., Beilin, L. J., and Dollery, C. T. (1970). Comparison of cardiorespiratory effects of isoprenaline and salbutamol in patients with bronchial asthma. Britısh Medical Journal, 1, 65. 